\title{
PENERIMAAN DAN PEMANFAATAN TEKNOLOGI INFORMASI PADA UKM KULINER DAN UKM KAIN TRADISIONAL PALEMBANG
}

\author{
Irma Salamah ${ }^{1}$, RD Kusumanto ${ }^{2}$ \\ ${ }^{1}$ Jurusan Teknik Elektro / Prodi Teknik Telekomunikasi, Politeknik Negeri Sriwijaya \\ Palembang, Indonesia \\ 2Jurusan Teknik Elektro / Prodi Teknik Elektronika, Politeknik Negeri Sriwijaya \\ Palembang, Indonesia \\ e-mail: irma.salamah@yahoo.com¹, manto_6611@yahoo.co.id²
}

\begin{abstract}
Abstrak
Penelitian ini bertujuan untuk mengeksplorasi bagaimana penerimaan dan pemanfaatan teknologi informasi pada UKM kuliner dan UKM kain tradisional Palembang. Sampel penelitian adalah karyawan/ti 70 UKM. Pengujian dilakukan dengan menggunakan path analysis. Hasil pengujian menunjukkan job fit mempunyai pengaruh langsung terkuat terhadap intention to use IT karyawan/ti UKM. Hal ini dikarenakan UKM di Palembang lebih banyak menggunakan teknologi informasi untuk membantu penyelesaian proses-proses administrasi. Dengan menerapkan teknologi informasi UKM-UKM tersebut merasakan proses bisnis berjalan lebih mudah, baik, dan lancar. Sehingga adanya peningkatan konsumen dan keuntungan. Teknologi informasi yang diterapkan juga tidak terlalu kompleks. Jika diberikan teknologi informasi yang kompleks, para karyawan/ti tidak mampu menggunakan teknologi informasi tersebut. Adopsi teknologi informasi akan dapat dengan cepat diterima oleh lingkup sosial apabila memiliki karateristik berupa tingkat penggunaan yang mudah, memberi manfaat dan memberi nilai tambah bagi individu maupun organisasi.
\end{abstract}

Kata kunci: persepsi kemanfaatan, persepsi kemudahan penggunaan, faktor sosial, kesesuaian tugas, kondisi yang memfasilitasi

\begin{abstract}
This study aims to explore how the acceptance and utilization of information technology on SMEs culinary and SMEs traditional cloth of Palembang. The sample of the study was employees 70 SMEs. Testing is done by using path analysis. Test results show that job fit has the strongest direct influence on intention to use IT employees SMEs. This is because SMEs in Palembang use more information technology to assist the completion of administrative processes. By applying information technology these SMEs feel the business process runs easier, well, and smoothly. So that there is an increase in consumers and profits. Information technology applied is also not too complex. If a complex information technology is provided, employees are unable to use the information technology. Adoption of information technology will be quickly accepted by the social scope if it has characteristics such as the level of easy use, benefits and added value for individuals and organizations.
\end{abstract}

Keywords : perceived usefulness, perceived ease of use, social factor, job fit, facilitating condition

\section{PENDAHULUAN}

Pada era teknologi saat ini, teknologi informasi semakin dibutuhkan oleh suatu organisasi, terutama oleh organisasi yang ingin berkembang dan dapat bersaing dengan organisasi lain.
Penerapan teknologi informasi dapat berpengaruh terhadap kinerja perusahaan baik pada satu bagian tertentu maupun pada setiap karyawan organisasi tersebut. Apabila teknologi informasi yang diterapkan telah sesuai maka hal tersebut berdampak 
positif pada suatu organisasi. Teknologi informasi dan komunikasi saat ini sudah merupakan bagian yang tidak dapat dipisahkan dari kehidupan manusia modern. Di era globalisasi sekarang ini, teknologi informasi dan komunikasi memegang peranan penting dalam berbagi aspek kehidupan manusia. Teknologi informasi dan komunikasi memberikan dampak yang sangat positif dalam berbagai hal, di antaranya: pendukung pengambilan keputusan; peningkatan efisiensi dan produktivitas; penunjang aktivitas pekerjaan dan belajar; dan bahkan dapat meningkatkan mutu hidup manusia [1].

Perkembangan teknologi informasi, komunikasi dan globalisasi ekonomi telah mendorong perkembangan manusia menjadi kreatif. Perkembangan industri telah menciptakan pola kerja, pola produksi dan pola distribusi yang murah dan efisien. Perkembangan teknologi telah membuat orang menjadi lebih produktif. Industri kreatif adalah industri dengan sumber daya terbarukan karena berfokus pada menciptakan inovasi dan kreativitas yang merupakan keunggulan kompetitif suatu bangsa dan memberikan dampak sosial yang positif. Berbeda dengan industri pertambangan di sektor minyak dan gas yang semakin lama semakin habis, industri kreatif berfokus pada penciptaan barang dan jasa dengan mengandalkan keahlian, bakat, dan kreativitas sebagai properti yang unik. Industri kreatif merupakan bagian integral dari ekonomi kreatif. Menurut departemen perdagangan republik Indonesia definisi industri kreatif didefinisikan sebagai "Industri yang berasal dari pemanfaatan kreativitas, keterampilan dan talenta individu untuk menciptakan kemakmuran dan ketenagakerjaan melalui penciptaan dan pemanfaatan daya kreatif dan kreativitas masyarakat [2].

UKM merupakan salah satu dari industri kreatif yang mempunyai peran sangat strategis. Namun ketatnya kompetisi, terutama menghadapi perusahaan besar dan pesaing modern lainnya telah menempatkan UKM dalam posisi yang tidak menguntungkan. Di Indonesia, sebagian besar UKM menjalankan usahanya dengan cara-cara tradisional, termasuk dalam produksi dan pemasaran. Namun demikian, masalah yang dihadapi oleh UKM di negara-negara berkembang sebenarnya bukanlah karena ukurannya, tetapi lebih karena isolasi yang menghambat akses UKM kepada pasar, informasi, modal, keahlian, dan dukungan institusional. Teknologi informasi yang berkembang sangat pesat datang dengan peluang-peluang baru yang dapat mengatasi sebagian masalah UKM tersebut. Meskipun peluang yang dibawa oleh teknologi informasi sangat besar, namun banyak penelitian yang telah dilakukan menunjukkan bahwa adopsi teknologi informasi oleh UKM masih rendah dibandingkan dengan perusahaanperusahaan besar. Menurut hasil studi lembaga riset AMI Partners, hanya 20\% UKM di Indonesia yang memiliki komputer [3].

UKM yang memiliki komputer dalam membantu sistem usahanya, berarti mereka telah memahami pentingnya teknologi informasi untuk meningkatkan produktivitas UKM yang nantinya akan bermuara pada pembentukan UKM yang berdaya saing. Bidang pemanfaatan TI pada UKM cukup bervariasi. Hampir seluruh UKM telah memanfaatkan $\mathrm{TI}$ untuk administrasi, browsing, dan email. Pemanfaatan TI untuk desain produk dan pemasaran juga cukup banyak dilakukan, sedangkan pemanfaatannya untuk proses produksi masih terbilang rendah dibanding bidang lainnya. Beberapa penelitian pemanfaatan TI pada UKM antara lain pada sistem keamanan [4], cloud computing [5], pemanfaatan website [6], dan lain-lain.

Adanya pemanfaatan teknologi informasi tentunya tidak terlepas dari bagaimana penerimaan teknologi informasi itu sendiri. Ada banyak teori yang telah dikembangkan untuk menjelaskan niat pengguna dalam menggunakan teknologi sistem informasi. Salah satu teori mengenai penerimaan teknologi informasi adalah Technology Acceptance Model (TAM). TAM awalnya diusulkan oleh [7] dan sebenarnya adalah teori layanan informasi yang menjadi model bagaimana pengguna 
menerima dan menggunakan teknologi tertentu [8]. TAM berasal dari teori tindakan beralasan (TRA), model perilaku yang dikembangkan oleh Ajzen dan Fishbein. Awalnya, TAM dikembangkan untuk menentukan perilaku adopsi pengguna sistem informasi komputer di tempat kerja [7] dan kemudian diperluas untuk mempelajari teknologi perilaku penerimaan teknologi baru dalam berbagai penelitian terkait teknologi. TAM mendalilkan bahwa adopsi pengguna teknologi informasi ditentukan oleh dua dimensi sikap terkait teknologi, yaitu : perceived usefulness (PU) dan perceived ease of use (PEOU). Menurut [7], perceived usefulness dan perceived ease of use akan berpengaruh sikap para pengadopsi terhadap penggunaan yang pada gilirannya akan mengarah pada niat mengadopsi teknologi. Model TAM telah dikembangkan oleh sejumlah peneliti dan telah diterapkan pada berbagai teknologi termasuk mobile learning [9], e-learning [10], [11], mobile cloud computing service [12], telekonferensi [13], pengukuran software [14], layanan pesan singkat [15], e-government [16], social media [17], e-commerce [18], dan lain-lain.

Pada saat ini UKM dituntut untuk melakukan perubahan guna meningkatkan daya saingnya agar dapat terus berjalan dan berkembang. Salah satunya adalah dengan cara pemanfaatan teknologi informasi (TI). Pemanfaatan $\mathrm{TI}$ dapat meningkatkan transformasi bisnis melalui kecepatan, ketepatan dan efisiensi pertukaran informasi dalam jumlah yang besar. Studi kasus di Eropa juga menunjukkan bahwa lebih dari $50 \%$ produktifitas dicapai melalui investasi di bidang TI. UKM dikatakan memiliki daya saing global apabila mampu menjalankan operasi bisnisnya secara reliable, seimbang, dan berstandar tinggi.

Permasalahan yang umum ditemui, banyak dari pelaku usaha masih enggan mengenal teknologi informasi untuk mengembangkan usahanya. Demikian juga halnya dengan UKM di Palembang. Dari hasil survey, hanya beberapa UKM di Palembang yang memanfaatkan teknologi informasi pada proses bisnisnya. Padahal pemanfaatan teknologi informasi dan jaringan internet semakin mudah dijangkau dan digunakan bahkan untuk orang awam sekalipun.

Penelitian ini bertujuan untuk mengetahui bagaimana penerimaan dan pemanfaatan teknologi informasi pada UKM di Palembang. UKM yang menjadi objek pada penelitian ini adalah UKM kuliner dan UKM kain tradisional Palembang. UKM kuliner dan UKM kain tradisional merupakan UKM yang paling banyak di Palembang.

Penelitian ini menggabungkan model penerimaan teknologi TAM [7] dengan pemanfaatan teknologi informasi [19] terhadap minat pengguna untuk menggunakan teknologi informasi.

\section{METODE}

Penelitian ini menggabungkan dua model yaitu model TAM (technology acceptance model) yang dibangun oleh [7] dan model pemanfaatan teknologi informasi [19].

TAM merupakan salah satu model penerimaan teknologi yang sering dipakai untuk penelitian dibidang adopsi teknologi informasi. Konsep TAM yang dikembangkan oleh [7], menawarkan berbagai landasan teoritis untuk mempelajari dan memahami pengguna dalam menerima dan menggunakan teknologi. Pada TAM ada dua dimensi sikap terkait teknologi yaitu : perceived usefulness (PU) dan perceived ease of use (PEOU). Sedangkan pemanfaatan teknologi informasi menurut model yang dikembangkan oleh [19], faktor-faktor yang mempengaruhi pemanfaatan teknologi informasi adalah faktor sosial, affect (perasaan individual), kompleksitas, kesesuaian tugas, konsekuensi jangka panjang, dan kondisi yang memfasilitasi pemanfaatan teknologi informasi. Tetapi tidak semua variabel pada model pemanfaatan teknologi informasi dipilih pada penelitian ini. Hal ini dikarenakan untuk menyesuaikan pada objek penelitian. 
Maka model penelitian ini dapat digambarkan seperti gambar 1 berikut ini :

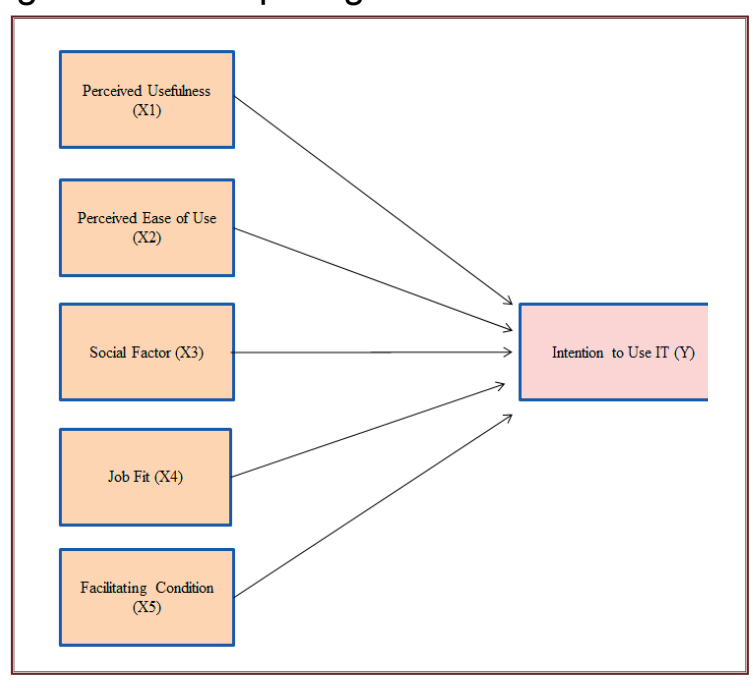

Gambar 1. Model penelitian

Populasi dalam penelitian ini adalah karyawan/ti UKM kuliner dan UKM kain tradisional Palembang yang telah menggunakan teknologi informasi dalam proses bisnisnya. Penggunaan teknologi informasi yang telah dilakukan adalah seperti pemanfaatan komputer pada proses administrasi, email, dan penjualan online. Dari hasil survey yang dilakukan, jumlah UKM di Palembang yang telah menggunakan teknologi informasi adalah \pm 50 UKM. Dari 50 UKM tersebut jumlah karyawan/ti yang dijadikan sample penelitian adalah 108. Semua populasi dijadikan sample. Dari 108 kuesioner yang disebarkan hanya 70 kuesioner yang dapat diolah. Sehingga sample yang diambil pada penelitian ini berjumlah 70 karyawan/ti UKM kuliner dan UKM kain tradisional Palembang.

\section{Teknik Pengumpulan Data}

1.Studi Lapangan (Field Research) : penulis langsung ke lapangan guna mengetahui permasalahan yang terjadi sekaligus untuk memperoleh data primer yang dibutuhkan yaitu dengan cara sebagai berikut:

a.wawancara : pengumpulan data dengan tanya jawab langsung dengan pihakpihak terkait yang dalam hal ini adalah pihak UKM. Hal ini dapat menunjang ketersediaan data yang dibutuhkan dalam penelitian ini.

b.angket (kuesioner) : penulis memberikan daftar pertanyaan yang berhubungan dengann masalah penelitian kepada responden dan tiap pertanyaan merupakan jawabanjawaban yang mempunyai makna dalam menguji hipotesis, kemudian diolah dan dianalisis.

2.Studi Kepustakaan (Library Research) : mengumpulkan data dengan cara membaca, mempelajari, dan menganalisa buku-buku yang ada hubungannya dengan masalah yang diteliti.

\section{Pengujian Kualitas Data}

Pengukuran variabel dalam penelitian ini dilakukan dengan tujuan agar hipotesis yang diajukan dapat diuji dan pertanyaan penelitian dapat dijawab. Dua kriteria utama untuk menguji seberapa baik instrument pengukuran yang digunakan yaitu dengan uji validitas dan uji reliabilitas. Uji validitas dalam penelitian ini dilakukan dengan menghitung korelasi antar skor dengan bantuan aplikasi SPSS. Pengujian validitas juga dilakukan untuk setiap butir pertanyaan yang digunakan dalam variabel. Suatu instrument dikatakan valid jika nilai corrected item total correlation > $r$ table [20]. Sedangkan uji reliabilitas hanya dapat dillakukan setelah suatu instrument dipastikan validitasnya. Uji reliabilitas dalam penelitian ini akan menggunakan bantuan aplikasi SPSS dengan melihat nilai koefisien Alpha atau Alpha Cronbach.suatu instrument dikatakan reliable jika nilai cronbach alpha > 6 [21].

\section{Pengujian Hipotesis}

Regresi dalam pengertian moderen menurut [22] ialah sebagai kajian terhadap ketergantungan satu variabel, yaitu variabel tergantung terhadap satu atau lebih variabel lainnya atau yang disebut sebagai variabel - variabel eksplanatori dengan tujuan untuk membuat estimasi dan / atau memprediksi rata - rata populasi atau nilai rata-rata variabel tergantung dalam 
kaitannya dengan nilai - nilai yang sudah diketahui dari variabel ekslanatorinya. Pada perkembangan berikutnya, para ahli statistik menambahkan isitilah regresi berganda (multiple regression) untuk menggambarkan proses dimana beberapa variabel digunakan untuk memprediksi satu variabel lainnya. Sebelum dianalisis data tersebut harus diuji apakah melanggar asumsi dasar yang telah ditentukan. Sebelum melakukan regresi harus dilakukan uji asumsi klasik. Uji asumsi klasik terdiri dari uji multikolinearitas, uji normalitas, dan uji heterokedastisitas. Uji normalitas untuk melihat apakah data terdistribusi normal (dengan grafik normal distribution), uji multikolinieritas untuk mengetahui ada atau tidaknya hubungan linier antar variable independen dalam model regresi (dengan nilai VIF < 10), dan uji heterokedastisitas untuk melihat apakah data menyebar secara acak atau tidak (dengan grafik scatter plot).

Pengujian hipotesis pada penelitian ini menggunakan analisis jalur (path analysis). Analisis jalur merupakan pengembangan dari analisis korelasi, yang dibangun dari diagram jalur yang dihipotesiskan oleh peneliti dalam menjelaskan mekanisme hubungan kausal antar variabel dengan cara menguraikan koefisien korelasi menjadi pengaruh langsung dan tidak langsung. Selain itu analisis jalur dapat dikatakan sebagai analisis regresi linier dengan variabelvariabel yang dibakukan. Oleh karena itu, koefisien jalur pada dasarnya merupakan koefisien beta atau regresi baku.

Pemilihan analisis jalur pada penelitian ini dikarenakan peneliti ingin mengetahui seberapa besar pengaruh langsung variabel independen terhadap variabel dependen. Besarnya pengaruh tersebut dapat dilihat dari koefisien jalur.

\section{Pengembangan Hipotesis Penelitian}

[7] mendefinisikan PU (Perceived usefulness) atau persepsi kegunaan sebagai sejauh mana seseorang meyakini bahwa penggunaan sebuah sistem tertentu akan memberikan kemanfaatan bagi kinerjanya. Dari definisi tersebut diketahui jika seseorang merasa percaya bahwa sistem berguna maka dia akan menggunakannya. Sebaliknya jika seseorang merasa percaya bahwa system informasi kurang berguna maka dia tidak akan menggunakannya. Dengan demikian PU akan berpengaruh pada sikap pengguna. Selain itu sikap pengguna terhadap suatu sistem juga dapat berpengaruh terhadap niat berperilaku. Hipotesis yang dibangun adalah:

$\mathrm{H} 1$ : perceived usefulness (PU) secara langsung berpengaruh terhadap intention to use IT

[7] mendefinisikan PEOU (Perceived Ease of Use) sebagai tingkat keyakinan seseorang bahwa dalam menggunakan sistem tertentu tidak diperlukan usaha yang keras. Meskipun usaha menurut setiap orang bebeda-beda tetapi pada umumnya untuk menghindari penolakan dari pengguna system atas sistem yang dikembangkan, maka sistem harus mudah diaplikasikan oleh pengguna tanpa mengeluarkan usaha yang dianggap memberatkan. Kemudahan penggunaan persepsian merupakan salah satu faktor dalam model TAM yang telah diuji dalam penelitian [7]. Hasil penelitian tersebut menunjukkan bahwa faktor ini terbukti dapat menjelaskan alasan seseorang dalam menggunakan sistem informasi dan menjelaskan bahwa sistem baru yang sedang dikembangkan diterima oleh pengguna. Ketika PEOU pengguna terhadap suatu produk tinggi, maka pengguna akan memiliki sikap positif terhadap produk tersebut. Maka hipotesis yang dapat dibangun adalah:

$\mathrm{H} 2$ : perceived ease of use secara langsung berpengaruh terhadap intention to use IT

[19] menjabarkan faktor sosial dalam bentuk besarnya dukungan teman sekerja, manajer senior, organisasi, organisasi, dan atasan pemakai. Hasil penelitian menemukan bahwa faktor sosial berpengaruh terhadap pemanfaatan 
personal computer (PC). Hipotesis yang dapat dibangun adalah:

H3 : social factor of use secara langsung berpengaruh terhadap intention to use IT

Menurut [19], bahwa untuk kegiatan jangka pendek yang berkaitan dengan kemampuan teknologi informasi dapat digunakan untuk meningkatkan performa pekerjaan seseorang. Unsur ini diistilahkan sebagai perceived job fit yaitu besar kecilnya keyakinan seseorang terhadap kemampuan teknologi informasi dalam meningkatkan performa kerja mereka. Hal ini didukung oleh hasil penelitian thompson 1991 yang menunjukkan adanya hubungan yang positif antara kesesuaian tugas (job fit) dengan penggunaan teknologi informasi. Hipotesis yang dapat dibangun adalah :

H4 : job fit secara langsung berpengaruh terhadap intention to use IT
[23] mendefinisikan kondisi yang memfasilitasi sebagai faktor-faktor objektif yang memudahkan jalannya suatu tindakan. Dalam konteks penggunaan teknologi informasi, motivasi untuk menggunakan teknologi informasi adalah adanya suatu fasilitas pendukung yang dapat mempengaruhi pemanfaatan sistem. Kondisi yang memfasilitasi merupakan suatu cara untuk menghilangkan atau mengurangi hambatan yang ada dalam diri individu dengan melatih pengguna dan membantu mereka bila menghadapi kesulitan. Hipotesis yang dapat dibangun adalah :

H5 : facilitating condition secara langsung berpengaruh terhadap intention to use IT

HASIL DAN PEMBAHASAN

Tabel 1. Hasil uji validitas $\mathrm{X} 1, \mathrm{X} 2, \mathrm{X} 3, \mathrm{X} 4, \mathrm{X} 5$, dan $\mathrm{Y}$

\begin{tabular}{|c|c|c|c|c|c|c|c|c|c|c|c|}
\hline \multicolumn{12}{|c|}{ CITC } \\
\hline $\mathrm{X} 1.1$ & 0,393 & X2.1 & 0,526 & X3.1 & 0,619 & X4.1 & 0,403 & $\mathrm{X5.1}$ & 0,706 & Y1.1 & 0,698 \\
\hline $\mathrm{X} 1.2$ & 0,590 & $\mathrm{X} 2.2$ & 0,579 & X3.2 & 0,686 & X4.2 & 0,665 & $\mathrm{X5.2}$ & 0,756 & Y1.2 & 0,808 \\
\hline X1.3 & 0,664 & $\mathrm{X} 2.3$ & 0,537 & X3.3 & 0,638 & X4.3 & 0,623 & X5.3 & 0,640 & Y1.3 & 0,709 \\
\hline X1.4 & 0,624 & $\times 2.4$ & 0,687 & X3.4 & 0,674 & X4.4 & 0,645 & X5.4 & 0,622 & Y1.4 & 0,581 \\
\hline & & $\times 2.5$ & 0,710 & & & X4.5 & 0,435 & X5.5 & 0,589 & & \\
\hline & & & & & & & & $\times 5.6$ & 0,646 & & \\
\hline
\end{tabular}

Tabel 2. Hasil uji reliabilitas X1, X2, X3, X4, X5, dan Y

\begin{tabular}{|c|c|}
\hline & Cronbach Alpha \\
\hline & 0,762 \\
\hline $\mathrm{X} 1$ & 0,811 \\
\hline $\mathrm{X} 3$ & 0,777 \\
\hline $\mathrm{X} 4$ & 0,826 \\
\hline $\mathrm{X} 5$ & 0,880 \\
\hline $\mathrm{Y}$ & 0,854 \\
\hline
\end{tabular}

Tabel 3. Nilai hasil regresi

\begin{tabular}{|l|c|c|c|c|}
\hline \multicolumn{1}{|c|}{ Variable } & Beta & Sig & VIF & Rsquare \\
\hline Perceived usefulness & 0,536 & 0,001 & 2,452 & \\
\cline { 1 - 3 } Perceived ese of use & $-0,059$ & 0,734 & 3,052 & \multirow{2}{*}{0,376} \\
\hline Social factor & 0,198 & 0,059 & 1,090 & \multirow{2}{*}{0,37} \\
\cline { 1 - 3 } Job fit & 0,581 & 0,001 & 2,754 & \\
\cline { 1 - 3 } Facilitating condition & $-0,539$ & 0,004 & 3,306 & \\
\hline
\end{tabular}




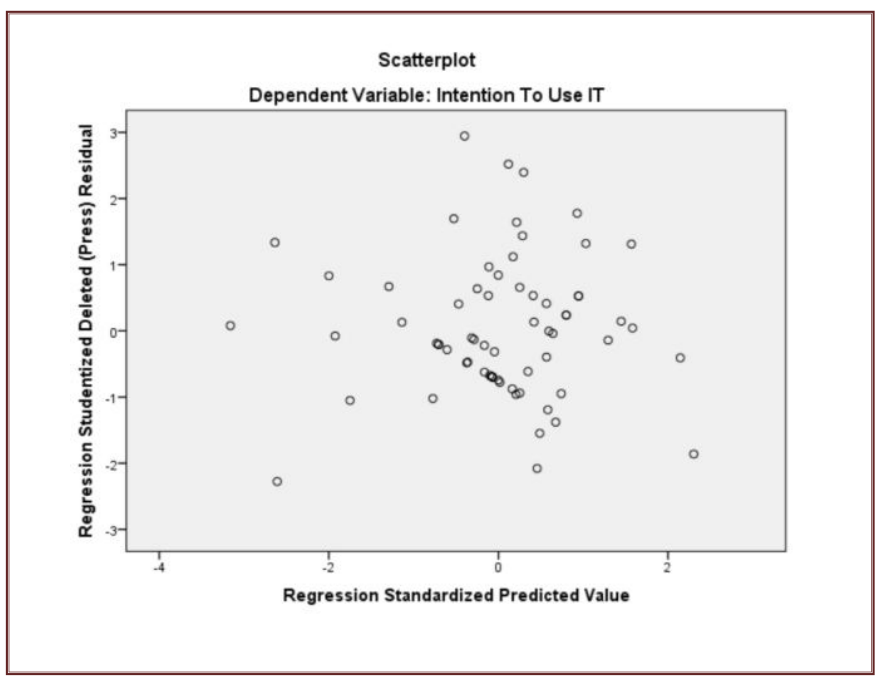

Gambar 2. Hasil uji normalitas

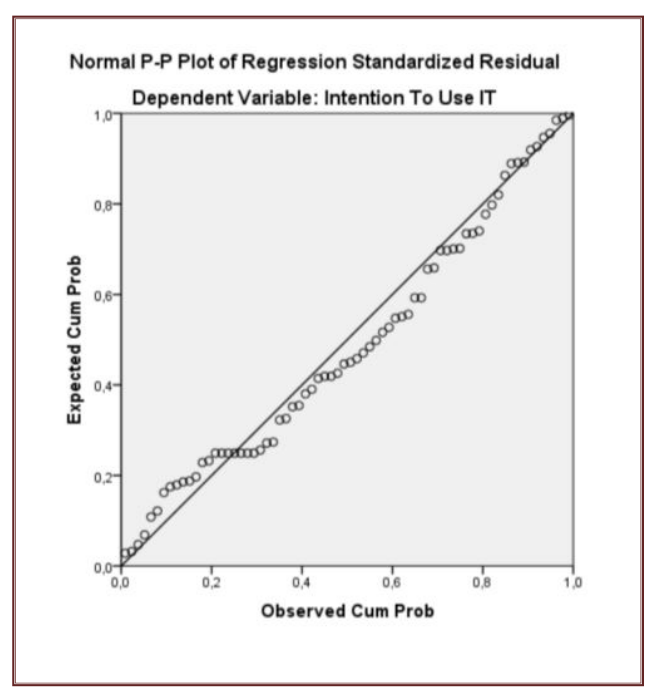

Gambar 3. Hasil uji heterokedastisitas

Dari tabel 1 terlihat hasil uji validitas untuk X1, X2, X3, X4, X5, dan $Y$ diperoleh $r$ hasil (corrected item-total correlation) $>r$ tabel ( $r$ tabel $=0,2352$ ). Dengan demikian maka variabel perceived usefulness, perceived ease of use, social factor, job fit, facilitating condition dan intention to use dinyatakan valid dan layak digunakan untuk penelitian.
Hasil uji reliabilitas (tabel 2) nilai cronbach alpha $\mathrm{X} 1, \mathrm{X} 2, \mathrm{X} 3, \mathrm{X} 4$, dan $\mathrm{Y}$ lebih besar dari $r$ tabel (cronbach alpha>r tabel). Dengan demikian maka perceived usefulness, perceived ease of use, social factor, job fit, facilitating condition dan intention to use dinyatakan reliabel dan layak digunakan untuk penelitian. 
Pada table 3 terlihat bahwa nilai VIF untuk persamaan adalah lebih kecil dari 10, sehingga dapat dikatakan bahwa tidak ditemukan adanya masalah multikolinearitas.

Dari gambar 2 terlihat bahwa data terdistribusi mendekati garis normal dan dari gambar 3 hasil uji heterokedastisitas menunjukkan data menyebar secara acak. Dari tabel 3 juga terlihat nilai $R$ square $=0,376$ yang berarti secara simultan variabel $\mathrm{X} 1, \mathrm{X} 2, \mathrm{X} 3, \mathrm{X} 4$, dan $\mathrm{X} 5$ memiliki kontribusi sebesar 37,6 persen dalam menjelaskan perubahan yang terjadi pada variabel $Y$ sedangkan sisanya sebesar 62,4 persen dijelaskan oleh variabel lain di luar model. Nilai $t$ untuk uji parsial terlihat bahwa variabel $X 1, X 4$, dan $X 5$ secara statistik memiliki pengaruh yang signifikan terhadap variabel $Y$ yang ditunjukkan oleh nilai Sig masing-masing lebih kecil dari $5 \%$ yaitu 0,001 untuk $X 1$ dan $X 4$, serta 0,004 untuk X5. Hipotesis 1, 4, dan 5 diterima. Variabel $\mathrm{X} 2$ dan $\mathrm{X} 3$ secara statistik tidak signifikan mempengaruhi variabel $Y$ yang terlihat dari nilai Sig. sebesar 0,734 (> 5\%) untuk variabel $X 1$ dan $0,059(>5 \%)$ untuk variabel $X 2$. Sehingga variabel $X 1$ dan $X 2$ kita eliminasi dari model. Hal ini berarti hipotesis 2 dan hipotesis 3 ditolak.

Persamaan strukturalnya adalah sebagai

berikut :

$$
\mathrm{Y}=0,536 \mathrm{X1}+0,581 \times 4-0,539 \times 5+\epsilon_{1}
$$

Model diagram jalurnya adalah sebagai berikut :

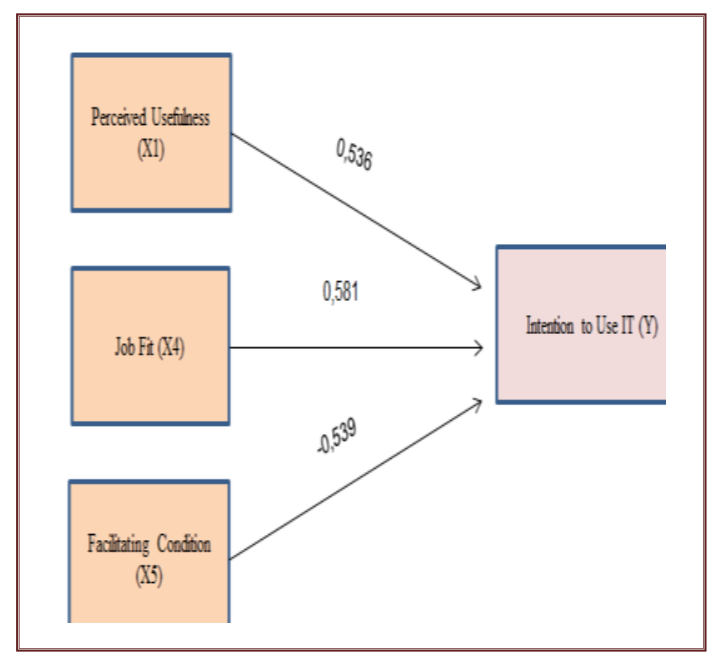

Gambar 4. Model diagram jalur
Dari gambar 4 terlihat job fit memiliki nilai koefisien jalur paling besar. Hal ini menunjukkan job fit memiliki pengaruh yang paling kuat terhadap intention to use IT. Kemudian diikuti oleh perceived usefulness dan facilitating condition.

\section{SIMPULAN}

Berdasarkan bukti-bukti empiris yang diperoleh maka disimpulkan bahwa perceived usefulness, job fit, dan facilitating condition berpengaruh secara langsung terhadap intention to use IT. Adanya pengaruh pada variabel penelitian, berdasarkan hasil dari survei kuesioner. Job fit menjadi faktor terkuat UKM Palembang untuk menggunakan teknologi informasi. Hal ini dikarenakan UKM di Palembang lebih banyak menggunakan teknologi informasi untuk membantu penyelesaian proses-proses administrasi seperti penjualan online dan pemesanan online. Sehingga pemanfaatan teknologi informasi akan membantu mempermudah dan mempercepat penyelesaian penjualan dan pembelian. Teknologi informasi juga dimanfaatkan untuk membuat website sehingga UKM-UKM tersebut lebih dikenal tidak hanya di Palembang tetapi juga di luar Palembang. Dengan adanya website UKMUKM tersebut dapat mempromosikan produk-produk yang mereka buat. Perceived usefulness menjadi faktor terkuat kedua UKM Palembang untuk menggunakan teknologi informasi. Hal ini dikarenakan UKM Palembang merasakan manfaat yang begitu besar setelah mereka menerapkan teknologi informasi pada proses bisnisnya. Dengan menerapkan teknologi informasi UKM-UKM tersebut merasakan proses bisnis berjalan lebih mudah, baik, dan lancar. Sehingga adanya peningkatan konsumen dan keuntungan. Facilitating condition menjadi faktor terakhir yang mempengaruhi UKM-UKM tersebut untuk menggunakan teknologi informasi. Para manajer UKM menerapkan teknologi informasi yang digunakan oleh UKM-UKM tersebut tidak terlalu kompleks. Software yang digunakan juga hanya Ms Office yang umum digunakan. Nilai negatif untuk variabel facilitating condition menyatakan kenaikan nilai facilitating condition akan 
menyebabkan penurunan minat untuk menggunakan teknologi informasi (intention to use IT). Hal ini dikarenakan para karyawan/ti UKM-UKM tersebut umumnya hanya berpendidikan SMA. Jika diberikan teknologi informasi yang kompleks, para karyawan/ti tidak mampu menggunakan teknologi informasi tersebut.

\section{REFERENSI}

[1] I. Salamah, "Utilization of It and the Effect on Individual Performance of Lecturers At State Polytechnic Sriwijaya," Ventura, vol. 15, no. 110, pp. 31-46, 2012.

[2] J. J. Siregar, R. A. Aryanti, W. Puspokusumo, and A. Rahayu, "Analysis of Affecting Factors Technology Acceptance Model in The Application Of Knowledge Management for Small Medium Enterprises in Industry Creative," Procedia Comput. Sci., vol. 116, pp. 500-508, 2017.

[3] F. Wahid and Nurulindarti, "Rendah, Adopsi Teknologi Informasi oleh UKM di Indonesia," Majalah PIP, 2007. [Online]. Available:

https://nurulindarti.wordpress.com/20 07/06/23/rendah-adopsi-teknologiinformasi-oleh-ukm-di-indonesia/. [Accessed: 12-Dec-2017].

[4] A. Freeman and L. Doyle, "The Utilization of Information Systems Security in SMEs in the South East of Ireland," in Management of the Interconnected World: ItAIS: The Italian Association for Information Systems, 1st ed., Physica-Verlag Heidelberg, 2010, p. pp 121-128.

[5] D. Assante, M. Castro, I. Hamburg, and S. Martin, "The Use of Cloud Computing in SMEs," Procedia Comput. Sci., vol. 83, pp. 12071212, 2016.

[6] O. Notta and A. Vlachvei, "Web Site Utilization in SME Business Strategy: The Case of Greek Wine SMEs," World J. Soc. Sci. Issue. Pp, vol. 3, no. 5, pp. 131-141, 2013.

[7] F. D. Davis, "Perceived Usefulness , Perceived Ease Of Use, And User Acceptance," MIS Q., vol. 13, no. 3, pp. 319-339, 1989.

[8] S. Yusuf Dauda and J. Lee, "Technology adoption: A conjoint analysis of consumers' preference on future online banking services," Inf. Syst., vol. 53, pp. 1-15, 2015.

[9] D. Mugo, K. Njagi, B. Chemwei, and J. Motanya, "The Technology Acceptance Model (TAM) and its Application to the Utilization of Mobile Learning Technologies," Br. J. Math. Comput. Sci., vol. 20, no. 4, pp. 1-8, 2017.

[10] R. Cheung and D. Vogel, "Predicting user acceptance of collaborative technologies: An extension of the technology acceptance model for elearning," Comput. Educ., vol. 63, pp. 160-175, 2013.

[11] D. Persico, S. Manca, and F. Pozzi, "Adapting the technology acceptance model to evaluate the innovative potential of e-learning systems," Comput. Human Behav., vol. 30, pp. 614-622, 2014.

[12] E. Park and K. J. Kim, "An integrated adoption model of mobile cloud services: Exploration of key determinants and extension of technology acceptance model," Telemat. Informatics, vol. 31, no. 3, pp. 376-385, 2014.

[13] N. Park, M. Rhoads, J. Hou, and K. M. Lee, "Understanding the acceptance of teleconferencing systems among employees: An extension of the technology acceptance model," Comput. Human Behav., vol. 39, pp. 118-127, 2014.

[14] L. G. Wallace and S. D. Sheetz, "The adoption of software measures: $A$ technology acceptance model (TAM) perspective," Inf. Manag., vol. 51, no. 2, pp. 249-259, 2014.

[15] A. Muk and C. Chung, "Applying the technology acceptance model in a two-country study of SMS advertising," J. Bus. Res., vol. 68, no. 1, pp. 1-6, 2015.

[16] A. A. Hamid, F. Z. A. Razak, A. A. Bakar, and W. S. W. Abdullah, "The Effects of Perceived Usefulness and Perceived Ease of Use on 
Continuance Intention to Use EGovernment," Procedia Econ.

Financ., vol. 35, no. October 2015, pp. 644-649, 2016.

[17] D. Z. Dumpit and C. J. Fernandez, "Analysis of the use of social media in Higher Education Institutions (HEls) using the Technology Acceptance Model," Int. J. Educ. Technol. High. Educ., vol. 14, no. 1, p. 5, 2017.

[18] R. Fayad and D. Paper, "The Technology Acceptance Model ECommerce Extension: A Conceptual Framework," Procedia Econ. Financ., vol. 26, no. 961, pp. 1000-1006, 2015.

[19] R. L. Thompson, C. A. Higgins, and J. M. Howell, "Personal Computing: Toward a Conceptual Model of Utilization," MIS Q., vol. 15, no. 1, p. 125, 1991.

[20] D. Priyatno, Mandiri Belajar Analisis Data Dengan SPSS. Jakarta: MediaKom, 2013.

[21] S. Uma, Metodelogi Penelitian Untuk Bisnis, 4th ed. Jakarta: Salemba Empat, 2006.

[22] D. N. Gujarati and D. C. Porter, Basic Econometrics. McGraw-Hill Irwin, 2009.

[23] H. C. Triandis, "Values, Attitudes, and Values," in Nebraska Symposium on Motivation, 1979: Beliefs, Attitudes and Values, 1980, p. 195-259. 